\title{
Age, Period and Cohort Analysis of Smoking Prevalence in Iranian Population over a 25-Year Period
}

\author{
Parisa Ghelichkhani, MSc'; Masoud Baikpour, MD $^{2}$; Kazem Mohammad, PhD³; Fattah Hama Rahim Fattah, MD ${ }^{4}$; Nazila Rezaei, MD $^{5}$; Naser \\ Ahmadi, MD'; Simin Darvish Noori Kalaki, PhD Student ${ }^{6}$; Mohammed I M Gubari, PhD'; Ali Rafei, PhD; Jalil Koohpayehzadeh, MD, PhD; \\ Mohammad Mehdi Gouya, MD; Mahmoud Yousefifard, PhD ${ }^{9^{*}}$; Michael E. Jones, PhD ${ }^{10}$; Mostafa Hosseini, PhD $^{3^{*}}$

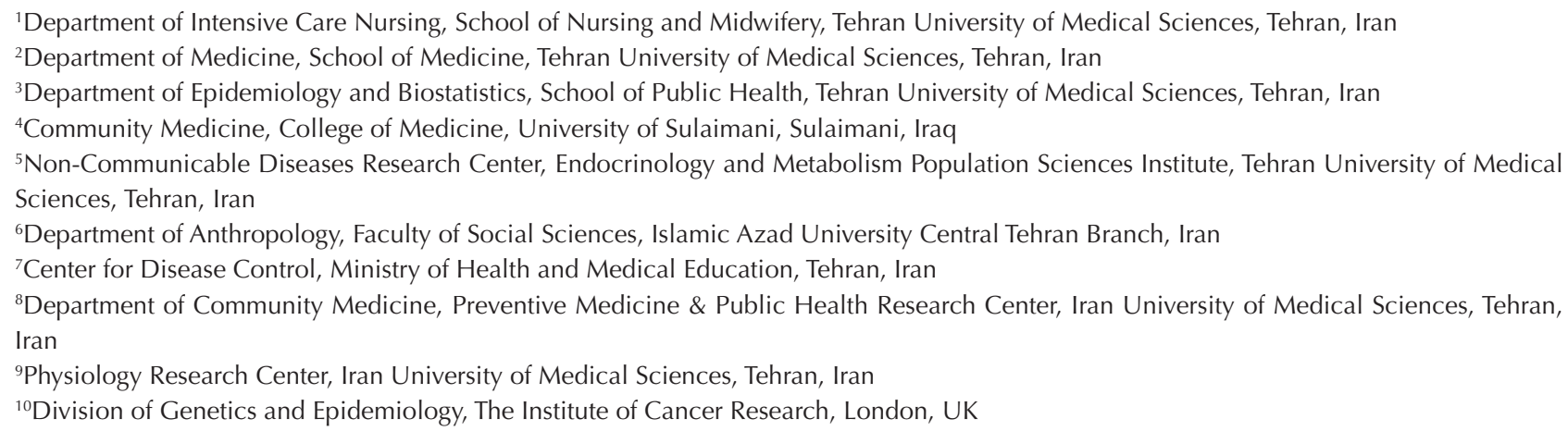

Abstract

Background: Current and daily smoking prevalence rates have been have investigated in several cross-sectional studies. However, analyses in terms of age-period-cohort (APC) have not been carried out. We assessed daily smoking dynamics over a 25-year period using the APC model.

Methods: In our analyses, we used data from 214,652 people aged 15 to 64 years, collected by national health surveys conducted in 1990-1991, 1999, 2005, 2007, 2011 and 2016. The Intrinsic Estimator model was used to analyze the impact of APC on daily smoking prevalence.

Results: Males were found to exhibit a higher prevalence of smoking compared to females $(26.0 \%$ against $2.7 \%)$. Prevalence of smoking increased by age, peaking at the age groups of 40-44 in men and 45-49 in women, followed by a decreasing trend. The 1990 period had the highest prevalence in both genders, and the 2016 period had the lowest. The coefficients of birth cohort effects showed different patter19s of fluctuations in the two genders with the maximum and minimum coefficients for men calculated in the 1966-1970 and 1991-95 birth cohorts, and for females the 1931-1935 and 1971-1975 birth cohorts, respectively. Conclusion: We showed the impact of APC on daily tobacco smoking prevalence, and these factors should be considered when dealing with smoking.

Keywords: Age-period-cohort analysis, Iran, Smoking

Cite this article as: Ghelichkhani P, Baikpour M, Mohammad K, Rahim Fattah FH, Rezaei N, Naser Ahmadi N, et al. Age, period and cohort analysis of smoking prevalence in Iranian population over a 25-year period. Arch Iran Med. 2021;24(1):7-14. doi: 10.34172/aim.2021.02.

Received: October 11, 2019, Accepted: November 18, 2020, ePublished: January 1, 2021

\section{Introduction}

Since 1990, each year smoking has taken the life of more than 5 million people, and in the year 2015 it was reported as one of the major risk factors of diseases and deaths globally. ${ }^{1}$ Recognized as a main preventable cause of death, smoking has significantly burdened health care systems all around the world, taking up 1.5\%-6.8\% of annual national health budgets which measures up to $0.2 \%-0.9 \%$ of the countries' gross domestic product. $^{2}$ The trend of smoking in Iranian population decreased in the last decade. The prevalence of smoking in 2000 was $13.5 \%$ which reached $11.3 \%$ in $2011 .^{3}$
Considering the gravity of this global health issue, various tobacco control policies and different interventions have been implemented widely in the past decade to tackle this epidemic, including increased tobacco taxes ${ }^{4}$ marketing restrictions, ${ }^{5}$ strong text and graphic warnings on cigarette packaging, ${ }^{6,7}$ prohibition of smoking at public places, ${ }^{8,9}$ and a wide range of smoking cessation programs. ${ }^{10}$

Accordingly, observing variations in smoking prevalence is of utmost importance in order to assess the effects of these interventions and modify them to yield optimal results. Therefore, various studies have aimed to evaluate the pattern of variations in smoking prevalence in differing

*Corresponding Authors: Mostafa Hosseini PhD; Department of Epidemiology and Biostatistics School of Public Health, Tehran University of Medical Sciences, Poursina Ave, Tehran, Iran; Tel: +982188989125, Fax: +982188989127, Email: mhossein110@yahoo.com;

Mahmoud Yousefifard, PhD; Physiology Research Center, School of Medicine, Iran University of Medical Sciences, Hemmat Highway, Tehran, Iran. Tel: +982186704771, Email: yousefifard.m@iums.ac.ir 
settings. ${ }^{11,12}$ Based on the latest World Health Organization (WHO) report, it seems that smoking prevalence follows different patterns in different populations, highlighting the significance of observing the trend of each society separately.

It should be also noted that the majority of the mentioned studies have only taken one aspect of temporal trends into account, while epidemiological studies include three entangled temporal dimensions of cohort, age and period effects when observing how variables behave over a duration. In this context, age effect reflects the effects of events that have affected subjects in a specific age group in comparison to others. Period effect is a reflection of events that have affected all the subjects at a specific period of time. Cohort effect mirrors the effects of events that have affected subjects with similar birth year. Together, these three effects can give a more accurate description for the trend of changes in a variable. ${ }^{13}$

In this regard, the present study performed age-periodcohort (APC) analysis for the first time in order to observe the pattern of variations in smoking prevalence in Iranian adolescents as well as adults aged 15 to 60 years over a period of 25 years.

\section{Materials and Methods}

\section{Study Approach}

To analyze the impact of APC on smoking prevalence in the population of Iranian adolescents and adults aged 15 to 64 years, data collected through six national health surveys conducted in 1990, 1999, 2005, 2007, 2011 and 2016 were obtained and pooled. Data collection methods of the six surveys are briefly described in the following. For further details about the methods of the first four surveys (1990-2007), refer to the study by Hosseini et al. ${ }^{14}$

\section{Records}

\section{0 and 1999 Health Surveys}

From June 1990 to March 1992, this first survey reported the smoking status of 25745 Iranian adolescents and adults aged 15 to 64 years. Also, the second survey was carried out from April 1999 to February 2000 and recorded the smoking status of 33,776 subjects aged 15-64 years with recorded data on smoking status. Samples were selected using random cluster sampling of households involving subjects aged 2-69 years, representing 1/1000 of the country's urban and rural populations.

\section{National Surveillance of Risk Factors for Non-communicable Diseases, 2005 and 2007}

Carried out in 2005, the first round of National Surveillance of Risk Factors of Non-Communicable Diseases recorded smoking status of 89388 adolescents and adults aged 15-64 years. The second round was conducted in 2007 and provided data on smoking status of 29893 adults aged 25 to 64 years. These studies were implemented in accordance with the WHO guidelines ${ }^{15}$ through collaborations involving forty medical schools from all over the country.

\section{National Surveillance of Risk Factors of Non-communicable} Diseases 2011

In the Sixth National Surveillance of Risk Factors of NonCommunicable Disease conducted in 2011, a multistage sampling framework was used in which counties were considered as primary sampling units, cities or villages as the secondary sampling units, households as sampling listing units and 6 to 70 year-old residents as the sampling elementary units. Using a Kish randomization method, at most two subjects were selected (one aged $<55$ years and the other $\geq 55$ years) per household. As for this study, the smoking status of 9,810 subjects aged 15-64 years were extracted from their database and included in the analyses.

\section{National Surveillance of Sisk Factors of Non-communicable Diseases 2016}

The most recent national surveillance study in Iran was also conducted according to the WHO STEPwise approach to Surveillance (STEPS) in 2016. Participants of this study were recruited from urban and rural areas of 30 provinces of Iran using systematic random sampling proportional to the adult population of each province. ${ }^{16}$ This survey recorded the smoking status of 26066 Iranian adolescents and adults aged 15 to 60 years.

\section{Smoking Definition}

These surveys evaluated the prevalence of daily tobacco smoking defined as individuals who reported smoking every day at the time of their participation in the study. ${ }^{17}$ No specific method was used to confirm the smoking status of the subjects and merely their self-declaration was used for their classification.

The surveys of 1990 and 1999 were received from Professor K. Mohammad who is a co-author. The other four surveys and their corresponding weights (due to sampling scheme) of all the surveys were received from the Iranian Ministry of Health.

\section{Statistical Analysis}

APC analysis, using Yang's intrinsic estimator (IE) approach $^{18,19}$ was performed to describe the impacts of APC on smoking prevalence among Iranian adolescents and adults. Briefly, the IE method takes into consideration the linear relationship between APC via singular value decomposition of matrices, thereby producing unbiased estimates with few time periods. Unlike other conventional regression techniques, it removes the influence of the design matrix on coefficient estimates. The advantages of the intrinsic estimator model include: providing estimable functions independent of selected constraints, higher statistical efficiency compared to other methods which 
limit data so as to elude identification issues, providing greater methodological accuracy and being theoretically appropriate.

Analyses were conducted separately for males and females, utilizing the "apc_ie" module from the STATA statistical software. The input of the "apc_ie" module in STATA is the aggregated prevalence of smoking according to age, gender, year of study (period of 5 years) and birth cohort (period-age). So at first, in order to account for the sampling scheme of surveys (as described above) a weighted analysis $^{20}$ was performed to calculate the prevalence of smoking of males and females for ages 15 to 64 years for each of the six used study data separately. These analyses gave 100 lines of data on age, prevalence of daily smoking and sex for each of these six surveys. Finally, in total 600 records from the data were pooled together.

Per the default setting of the "apc_ie" module, the study periods were put in the order of 5-year intervals. Therefore, the calculated prevalence for the study years 1999, 2003 together with 2007, 2011 and 2016 were taken as reasonable estimates of periods 2000, 2005, 2010 and 2015. To complete the data for APC analysis as fiveyear period, the prevalence of smoking for the different age groups of males and females for the period of 1995 were predicted. The aggregated data of prevalence for other study periods and fractional polynomial model were used for predicting 100 prevalence data for ages 15 to 64 years of males and females for the period of 1995. Finally, the APC analysis was performed separately for both sexes using the "apc_ie" module in STATA. Afterwards, the corresponding coefficients and 95\% confidence intervals (95\% CI) were presented.

\section{Results}

Data from a total of 214652 individuals aged 15 to 64 years $(48.4 \%$ males $)$ were included in our analyses. Table 1 demonstrates the number of participants included from each of these surveys by their gender. Accordingly, the 2005 study accounted for the highest percentage (41.7\%) of our studied population, whereas individuals included from the 2011 study comprised the smallest proportion with $4.6 \%$ of the sample size. Also, Table 1 shows that the total percentage of missing data were only $1.1 \%$ and ignored in the analysis.
Males were found to have a higher prevalence of smoking compared to females $(26.0 \%$ against $2.7 \%)$. Table 2 presents the prevalence of smoking by age and gender for each of the six surveys. Based on these figures, the prevalence of smoking in men rose with increasing age and reached its maximum of $35.9 \%$ in the age group 40-44 years and then declined to reach $26.0 \%$ for the age of 60-64. As for women, the prevalence showed a constant increase from $0.3 \%$ at the age of $15-19$ to $4.4 \%$ at 45-49 years. It then fluctuated and eventually reached its maximum rate of $6.0 \%$ at the age group of 60-64 years. The 1990 period was found to have the highest smoking prevalence in both genders $(31.1 \%$ in males and $5.4 \%$ in females), while the prevalence was reported to be lowest in both genders of individuals included from the 2016 period (19.5\% in males and $1.0 \%$ in females).

The prevalence of smoking by birth cohort and gender for each of these surveys is presented in Table 3. Subjects born in the birth cohort of 1931-1935 to 2000-2005 were included in our analyses, totaling fifteen 5-year birth cohorts. Follow-up was conducted only for participants of five birth cohorts (1956 to 1980) all through the period of 25 years. The estimated coefficients for APC impact on smoking prevalence are presented separately for the two genders in Table 4 and Figure 1.

\section{The APC Changes \\ Impact of Age}

The coefficient for the effect of age on smoking prevalence showed an increasing trend among men, from a minimum of $-19.4(95 \%$ CI: $-21.4,-17.5)$ at the age of 15 to its maximum of $7.1(95 \% \mathrm{CI}: 5.3,8.9)$ at the age group 40-44, and afterwards followed a decreasing trend to reach -1.3 (95\% CI: $-3.3,0.7)$ at the age of $60-64$. The female data also showed an increasing trend from -3.4 (95\% CI: $-4.6,-2.2)$ at age 15 to its maximum of 2.0 (95\% CI: 1.0 , 3.1 ) at age 45 , followed by a minor drop and then rise to $1.9(95 \% \mathrm{CI}: 0.7,3.2)$ at the age of 60-64 (Figure 1A and 1B).

\section{Period Effects}

The coefficients calculated for the effect of period on the prevalence of smoking fluctuated in women, starting with a drop, a rise, and again a decline to their minimum

Table 1. Demography of Study Population

\begin{tabular}{|c|c|c|c|c|c|}
\hline Period & Male (\%) & Female (\%) & Total $(\%)$ & Percentage of Missing & Percentage From Total \\
\hline 1990 & $12007(46.7 \%)$ & $13712(53.3 \%)$ & $25719(100 \%)$ & $3.7 \%$ & $12.0 \%$ \\
\hline 1999 & $15466(45.8 \%)$ & $18310(54.2 \%)$ & $33776(100 \%)$ & $1.2 \%$ & $15.7 \%$ \\
\hline 2003 & $45073(50.4 \%)$ & $44315(49.6 \%)$ & $89388(100 \%)$ & $0.2 \%$ & $41.7 \%$ \\
\hline 2007 & $14930(49.9 \%)$ & $14963(51.1 \%)$ & $29893(100 \%)$ & $0.9 \%$ & $13.9 \%$ \\
\hline 2011 & $4082(41.6 \%)$ & $5728(58.4 \%)$ & $9810(100 \%)$ & $0.8 \%$ & $4.6 \%$ \\
\hline 2016 & $12322(47.3 \%)$ & $13744(52.7 \%)$ & $26066(100 \%)$ & $1.7 \%$ & $12.1 \%$ \\
\hline Total & $103880(48.4 \%)$ & $110772(51.6 \%)$ & $214652(100 \%)$ & $1.1 \%$ & $100 \%$ \\
\hline
\end{tabular}


Table 2. Daily Smoking Prevalence in Terms of Age, Gender and Year

\begin{tabular}{|c|c|c|c|c|c|c|c|}
\hline \multirow{2}{*}{ Ages (y) \& Gender } & \multicolumn{7}{|c|}{ Period } \\
\hline & 1990 & 1999 & 2003 & 2007 & 2011 & 2016 & Total \\
\hline \multicolumn{8}{|l|}{ Male } \\
\hline $15-19$ & 3.0 & 2.2 & 2.5 & 3.1 & 2.4 & 2.9 & 2.7 \\
\hline $20-24$ & 19.2 & 15.8 & 10.8 & 14.7 & 5.5 & 4.7 & 11.8 \\
\hline $25-29$ & 34.6 & 29.0 & 19.5 & 26.5 & 13.9 & 12.3 & 22.6 \\
\hline $30-34$ & 40.5 & 33.7 & 28.6 & 28.8 & 26.9 & 16.9 & 29.2 \\
\hline $35-39$ & 40.0 & 39.8 & 33.2 & 33.4 & 31.4 & 23.9 & 33.6 \\
\hline $40-44$ & 37.5 & 36.9 & 35.9 & 41.0 & 38.9 & 25.1 & 35.9 \\
\hline $45-49$ & 36.4 & 31.7 & 34.6 & 39.0 & 32.6 & 28.3 & 33.8 \\
\hline $50-54$ & 34.2 & 28.2 & 32.2 & 38.4 & 33.4 & 30.2 & 32.8 \\
\hline $55-59$ & 33.4 & 32.2 & 29.1 & 33.9 & 27.9 & 26.4 & 30.5 \\
\hline $60-64$ & 31.4 & 25.5 & 25.8 & 27.1 & 22.6 & 23.6 & 26.0 \\
\hline Total & 31.1 & 27.6 & 25.3 & 28.7 & 23.6 & 19.5 & 26.0 \\
\hline \multicolumn{8}{|l|}{ Female } \\
\hline $15-19$ & 0.5 & 0.1 & 0.5 & 0.1 & 0.2 & 0.2 & 0.3 \\
\hline $20-24$ & 0.9 & 0.2 & 1.0 & 0.5 & 0.5 & 0.7 & 0.6 \\
\hline $25-29$ & 2.1 & 0.4 & 2.2 & 1.0 & 0.4 & 0.5 & 1.1 \\
\hline $30-34$ & 3.6 & 0.6 & 2.7 & 0.5 & 1.0 & 0.6 & 1.5 \\
\hline $35-39$ & 3.5 & 1.2 & 3.5 & 0.5 & 1.6 & 0.6 & 1.8 \\
\hline $40-44$ & 5.4 & 2.1 & 4.5 & 9.2 & 0.7 & 0.6 & 3.8 \\
\hline $45-49$ & 8.1 & 2.8 & 4.8 & 8.1 & 0.9 & 1.5 & 4.4 \\
\hline $50-54$ & 8.6 & 2.7 & 5.8 & 3.1 & 1.8 & 1.0 & 3.8 \\
\hline $55-59$ & 9.5 & 4.1 & 5.8 & 3.1 & 1.5 & 2.5 & 4.4 \\
\hline $60-64$ & 12.2 & 3.9 & 6.2 & 8.5 & 3.9 & 1.1 & 6.0 \\
\hline Total & 5.4 & 1.8 & 3.7 & 3.3 & 1.2 & 1.0 & 2.7 \\
\hline
\end{tabular}

values, while the calculated coefficients in men exhibited a declining pattern during the studied period. Maximum coefficients in both genders (male $=3.1,95 \% \mathrm{CI}: 1.8,4.5$; female $=2.0$, 95\% CI: $1.2,2.9$ ) were observed in 1990, while the 2016 period had the lowest coefficients (male $=-6.0,95 \% \mathrm{CI}:-7.4,-4.5$; female $=-2.0,95 \% \mathrm{CI}:-2.8$, -1.1) (Figure 1C and 1D).

\section{Birth Cohort Effects}

The impact of birth coefficients on the prevalence of smoking exhibited different patterns of fluctuations in the two genders. Among men, the maximum and minimum coefficients were calculated for the 1966-70 (4.8, 95\%CI: $2.8,6.8)$ and 1991-1995 (-6.9, 95\% CI: -9.2, -4.7) birth cohorts. As for females, the coefficient was found to be highest for the 1931-1935 (4.7, 95\% CI: 1.9, 7.6) birth cohort and lowest for the 1971-1975 (-2.2, 95\% CI: -3.4, -0.9) birth cohort (Figure 1E and $1 \mathrm{~F}$ ).

\section{Discussion}

The present study is the first survey that applied the APC model to investigate the 25-year dynamics of smoking prevalence among Iranian adolescents and adults aged 15-65 years. In its 2015 global report, the WHO used the data gathered through five national surveys conducted during a six-year period, in 2005, 2007, 2008, 2009 and 2011 , to describe the trends of smoking prevalence of Iranians whose age fell between 15 and 64 years. ${ }^{11}$ The source of three of the used surveys in this report (2005, 2007 and 2011) are the same with the current study, but the figures on prevalence of smoking reported by us in Table 2 and those by the WHO $2015^{11,12}$ are slightly different. The differences can be mainly due to our weighted analysis of prevalence and/or the number of data used for the WHO report which is not clear on the corresponding report.

Our results showed that the age-standardized prevalence of daily smoking in Iranian males was similar to that of a recent analysis by the Global Burden of Disease $(26.0 \%$ vs. $25.0 \%$ ) while there was a marked difference for females $(2.7 \% \text { vs. } 5.4 \%)^{21}$ Furthermore, the rate of smoking in males in our study was similar to those of Middle Eastern countries including Turkey and Egypt. Comparison was not made with developed countries such as the United States, United Kingdom and Canada since these countries have a very different history regarding the tobacco epidemic. The price of tobacco has been reported to be far lower in developing countries compared to developed nations, ${ }^{22}$ which could be considered a possible reason for the observed difference. It has also been estimated that a 70\% increase in tobacco price could prevent $25 \%$ of expected 
Table 3. Daily Smoking Prevalence in Terms of Birth Cohort, Study Year and Sex

\begin{tabular}{|c|c|c|c|c|c|c|c|}
\hline \multirow{2}{*}{$\begin{array}{l}\text { Cohorts \& } \\
\text { Gender }\end{array}$} & \multicolumn{7}{|c|}{ Study Year } \\
\hline & 1990 & 1999 & 2003 & 2007 & 2011 & 2016 & Total \\
\hline \multicolumn{8}{|l|}{ Male } \\
\hline 1931-1935 & 31.4 & & & & & & 31.4 \\
\hline 1936-1940 & 33.4 & & & & & & 33.4 \\
\hline 1941-1945 & 34.2 & 25.5 & & & & & 30.3 \\
\hline 1946-1950 & 36.4 & 32.2 & 25.8 & 27.1 & & & 30.9 \\
\hline 1951-1955 & 37.5 & 28.2 & 29.1 & 33.9 & 22.6 & & 30.7 \\
\hline 1956-1960 & 40.0 & 31.7 & 32.2 & 38.4 & 27.9 & 23.6 & 32.4 \\
\hline 1961-1965 & 40.5 & 36.9 & 34.6 & 39.0 & 33.4 & 26.4 & 34.9 \\
\hline 1966-1970 & 34.6 & 39.8 & 35.9 & 41.0 & 32.6 & 30.2 & 35.7 \\
\hline 1971-1975 & 19.2 & 33.7 & 33.2 & 33.4 & 38.9 & 28.3 & 31.1 \\
\hline 1976-1980 & 3.0 & 29.0 & 28.6 & 28.8 & 31.4 & 25.1 & 24.3 \\
\hline 1981-1985 & & 15.8 & 19.5 & 26.5 & 26.9 & 23.9 & 22.5 \\
\hline 1986-1990 & & 2.2 & 10.8 & 14.7 & 13.9 & 16.9 & 11.7 \\
\hline 1991-1995 & & & 2.5 & 3.1 & 5.5 & 12.3 & 5.9 \\
\hline 1996-2000 & & & & & 2.4 & 4.7 & 3.6 \\
\hline 2000-2005 & & & & & & 2.9 & 2.9 \\
\hline Total & 31.1 & 27.6 & 25.3 & 28.7 & 23.6 & 19.5 & 26.0 \\
\hline \multicolumn{8}{|l|}{ Female } \\
\hline 1931-1935 & 12.2 & & & & & & 12.2 \\
\hline 1936-1940 & 9.5 & & & & & & 9.5 \\
\hline 1941-1945 & 8.6 & 3.9 & & & & & 6.5 \\
\hline 1946-1950 & 8.1 & 4.1 & 6.2 & 8.5 & & & 6.5 \\
\hline 1951-1955 & 5.4 & 2.7 & 5.8 & 3.1 & 3.9 & & 4.2 \\
\hline 1956-1960 & 3.5 & 2.8 & 5.8 & 3.1 & 1.5 & 1.1 & 3.0 \\
\hline 1961-1965 & 3.6 & 2.1 & 4.8 & 8.1 & 1.8 & 2.5 & 3.8 \\
\hline 1966-1970 & 2.1 & 1.2 & 4.5 & 9.2 & 0.9 & 1.0 & 3.1 \\
\hline 1971-1975 & 0.9 & 0.6 & 3.5 & 0.5 & 0.7 & 1.5 & 1.3 \\
\hline 1976-1980 & 0.5 & 0.4 & 2.7 & 0.5 & 1.6 & 0.6 & 1.1 \\
\hline 1981-1985 & & 0.2 & 2.2 & 1.0 & 1.0 & 0.6 & 1.0 \\
\hline 1986-1990 & & 0.1 & 1.0 & 0.5 & 0.4 & 0.6 & 0.5 \\
\hline 1991-1995 & & & 0.5 & 0.1 & 0.5 & 0.5 & 0.4 \\
\hline 1996-2000 & & & & & 0.2 & 0.7 & 0.4 \\
\hline 2000-2005 & & & & & & 0.2 & 0.2 \\
\hline Total & 5.4 & 1.8 & 3.7 & 3.3 & 1.2 & 1.0 & 2.7 \\
\hline
\end{tabular}

premature deaths from tobacco. ${ }^{22}$ Therefore, we propose an upward review in tobacco taxes; an approach which has yielded significant outcomes in previous studies ${ }^{23-26}$ as one of the ways of reducing the prevalence.

We showed that daily smoking prevalence increased among young Iranian adults with increasing age, and the rate showed a slight increase in the more recent periods and birth cohorts. Possible reasons for this change could be the ban on public sale and use of tobacco enforced by the government in 1997, the Vice President's decree in 2002, and the Comprehensive National Tobacco Control Law adopted in $2006 .^{27}$

Prevalence was also higher for males compared to females. In general, smoking is more common in men than women worldwide. $^{21}$ This difference is more prominent in the
Iranian society. Cigarette smoking stigma in Iranian culture causes women to smoke less than men. In addition, the lower prevalence of smoking in women could be attributed to the conservative Iranian society in which the practice of smoking among females is usually frowned upon as an unacceptable behavior. This could lead to underreporting of smoking among the female gender as shown in a study by Sarafzadegan et al, in which a significant difference was observed between the rates of self-report and chemical indices of smoking in females (1.3\% versus $6.7 \%){ }^{28}$ Daily smoking prevalence in older women was markedly high. This could likely be due to marital status and low educational level of older compared to younger women. ${ }^{29-31}$ In addition, widowhood or divorce are more common in older women than younger women, which in part affects 
Table 4. Intrinsic Estimates of Prevalence of Daily Cigarette Smoking of Iranian by Sex

\begin{tabular}{|c|c|c|c|c|c|c|c|c|}
\hline \multirow{2}{*}{ Age, Period and Cohort } & \multicolumn{4}{|c|}{ Male } & \multicolumn{4}{|c|}{ Female } \\
\hline & Coefficients* & \multicolumn{2}{|c|}{$95 \% \mathrm{Cl}$} & $P$ & Coefficients* & \multicolumn{2}{|c|}{$95 \% \mathrm{Cl}$} & $P$ \\
\hline $15-19$ & -19.4 & -21.3 & -17.5 & $<0.001$ & -3.4 & -4.6 & -2.2 & $<0.001$ \\
\hline $20-24$ & -9.5 & -11.3 & -7.8 & $<0.001$ & -2.5 & -3.5 & -1.4 & $<0.001$ \\
\hline $25-29$ & 0.04 & -1.7 & 1.8 & 0.961 & -1.4 & -2.5 & -0.3 & 0.010 \\
\hline $30-34$ & 4.7 & 2.9 & 6.5 & $<0.001$ & -0.8 & -1.9 & 0.3 & 0.156 \\
\hline $35-39$ & 6.5 & 4.7 & 8.3 & $<0.001$ & -0.2 & -1.3 & 0.9 & 0.747 \\
\hline $40-44$ & 7.1 & 5.3 & 8.9 & $<0.001$ & 1.6 & 0.5 & 2.7 & 0.005 \\
\hline $45-49$ & 4.9 & 3.1 & 6.7 & $<0.001$ & 2.0 & 1.0 & 3.1 & $<0.001$ \\
\hline $50-54$ & 4.2 & 2.4 & 6.0 & $<0.001$ & 1.4 & 0.3 & 2.5 & 0.014 \\
\hline $55-59$ & 2.8 & 1.2 & 4.5 & 0.001 & 1.3 & 0.3 & 2.3 & 0.011 \\
\hline $60-64$ & -1.3 & -3.3 & 0.7 & 0.204 & 1.9 & 0.7 & 3.2 & 0.002 \\
\hline \multicolumn{9}{|l|}{ Period } \\
\hline 1990 & 3.1 & 1.8 & 4.5 & $<0.001$ & 2.0 & 1.2 & 2.9 & $<0.001$ \\
\hline 1995 & 1.8 & 0.4 & 3.2 & 0.010 & 0.9 & 0.1 & 1.7 & 0.037 \\
\hline 2000 & 1.2 & -0.2 & 2.6 & 0.084 & -0.7 & -1.6 & 0.1 & 0.096 \\
\hline 2005 & 1.3 & 0.3 & 2.4 & 0.015 & 1.1 & 0.5 & 1.8 & 0.001 \\
\hline 2010 & -1.5 & -2.9 & -0.1 & 0.030 & -1.4 & -2.2 & -0.6 & 0.001 \\
\hline 2015 & -6.0 & -7.4 & -4.5 & $<0.001$ & -2.0 & -2.8 & -1.1 & $<0.001$ \\
\hline \multicolumn{9}{|l|}{ Cohort } \\
\hline 1931-1935 & 3.7 & -1.0 & 8.3 & 0.126 & 4.7 & 1.9 & 7.6 & 0.001 \\
\hline $1936-1940$ & 2.0 & -1.1 & 5.1 & 0.214 & 2.4 & 0.5 & 4.3 & 0.013 \\
\hline 1941-1945 & 0.5 & -2.2 & 3.2 & 0.724 & 0.7 & -0.9 & 2.4 & 0.392 \\
\hline 1946-1950 & 1.1 & -1.2 & 3.4 & 0.340 & 0.4 & -1.0 & 1.8 & 0.587 \\
\hline 1951-1955 & 0.3 & -1.8 & 2.4 & 0.758 & -1.3 & -2.6 & -0.1 & 0.040 \\
\hline $1956-1960$ & 2.3 & 0.3 & 4.3 & 0.023 & -2.0 & -3.2 & -0.8 & 0.001 \\
\hline 1961-1965 & 4.3 & 2.3 & 6.3 & $<0.001$ & -1.1 & -2.3 & 0.1 & 0.070 \\
\hline 1966-1970 & 4.8 & 2.8 & 6.8 & $<0.001$ & -1.3 & -2.5 & -0.04 & 0.044 \\
\hline 1971-1975 & 2.3 & 0.3 & 4.3 & 0.022 & -2.2 & -3.4 & -0.9 & $<0.001$ \\
\hline 1976-1980 & -2.0 & -3.8 & -0.1 & 0.042 & -1.6 & -2.8 & -0.5 & 0.005 \\
\hline 1981-1985 & -3.5 & -5.5 & -1.5 & $<0.001$ & -0.9 & -2.1 & 0.3 & 0.154 \\
\hline 1986-1990 & -6.88 & -8.97 & -4.80 & $<0.001$ & -0.7 & -1.9 & 0.6 & 0.299 \\
\hline 1991-1995 & -6.94 & -9.19 & -4.70 & $<0.001$ & -0.3 & -1.6 & 1.1 & 0.714 \\
\hline 1996-2000 & -4.3 & -7.3 & -1.3 & 0.005 & 1.3 & -0.6 & 3.1 & 0.173 \\
\hline 2000-2005 & 2.4 & -2.6 & 7.3 & 0.346 & 1.8 & -1.2 & 4.8 & 0.238 \\
\hline Constant & 26.0 & 25.3 & 26.8 & $<0.001$ & 3.5 & 3.1 & 4.0 & $<0.001$ \\
\hline
\end{tabular}

* The decreasing coefficients show decreasing prevalence of smoking while increasing coefficients show increasing smoking prevalence.

their mental health and leads to depression. The higher prevalence of depression in old age may be the cause of the higher rate of smoking in old women. ${ }^{31}$

Regarding drawbacks, one is lack of adjustment of APC analyses for other demographic factors except gender, as these data were not collected in some surveys. Another limitation was possible small differences in performance of operating teams in different surveys, as the central teams responsible for data collection changed in different surveys during the period of 25 years when these six surveys were carried out. Also, the intrinsic model was used in 5-year intervals. But the time intervals between the surveys were varied, so the prevalence rates computed for study years 1991, 1999 and 2011 were taken as estimations for years
1990, 2000 and 2010. The average of the prevalence rates for the years 2003 and 2007 was used for 2005. Besides, by fitting a regression model, we estimated the corresponding prevalence for 1995. However, in the overall APC analysis for this study, the trends in coefficients of age, period and cohort of these approximations were fine and errors were negligible.

In conclusion, the findings from the present study showed that the prevalence of daily tobacco smoking was affected by age, period and birth cohort. The prevalence of daily tobacco smoking increased with increasing age. This observation is most evident in women. However, during the period 1990-2015, the overall prevalence of smoking decreased in both gender. In addition, a slight increase 

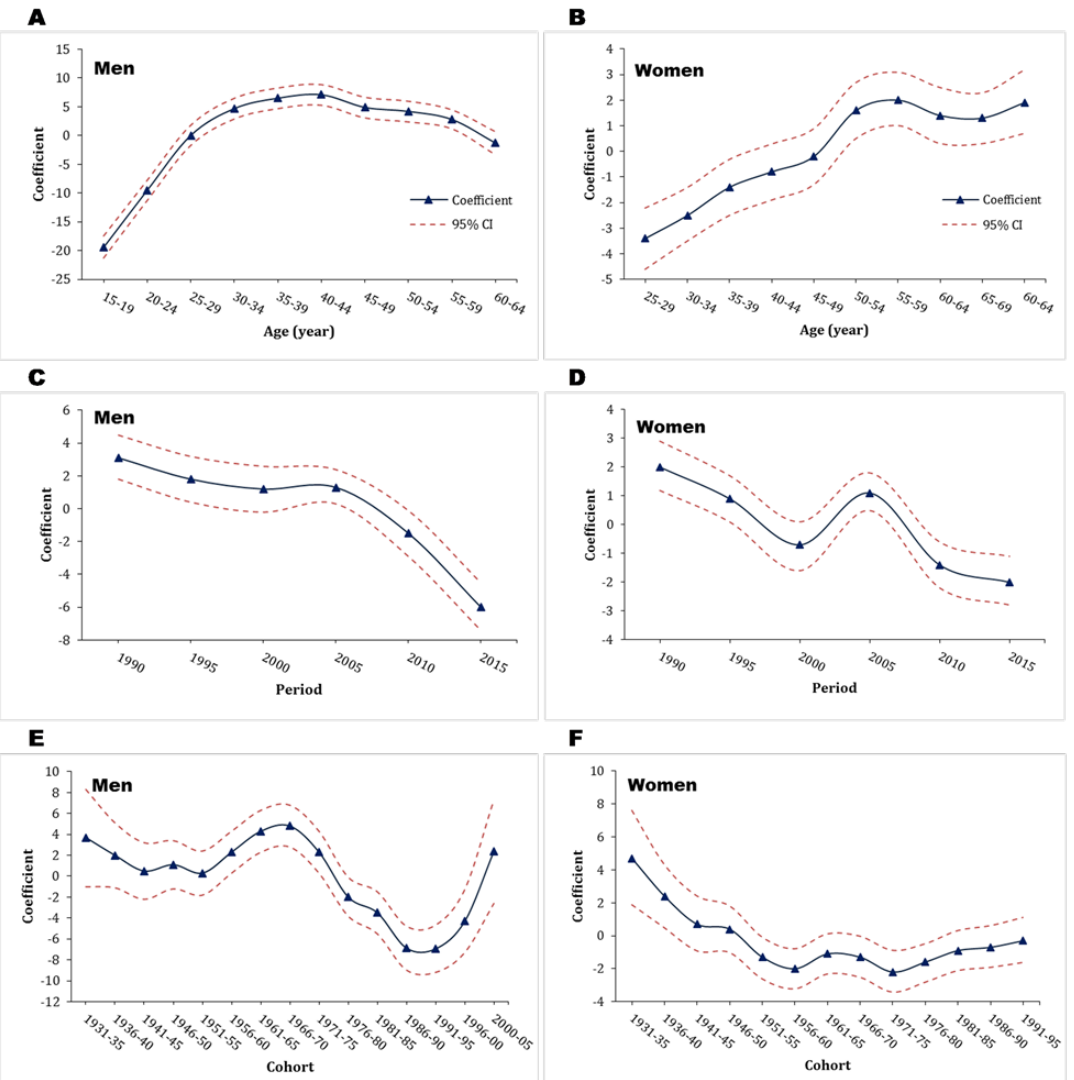

Figure 1. Impact of Age (A and B), Period (C and D), and Birth Cohort (E and F) on the Prevalence of Daily Smoking. The decreasing slope shows the decreasing prevalence of smoking and the increasing slope shows the increasing smoking prevalence.

in the prevalence of smoking was observed in the more recent periods and birth cohorts. Therefore, policy makers should put these factors into consideration in their bid to address issues arising from smoking.

\section{Authors' Contribution}

Conceptualization, $\mathrm{MH}, \mathrm{PG}, \mathrm{MY}, \mathrm{MB}$ and $\mathrm{KM}$; methods, $\mathrm{MH}, \mathrm{PG}$, $M Y, M B$ and $K M$; analyses, MH, MB, MY, KM, AR, NA, NR, SDNK, JK and MMG; write up, MH, MB, MAE, PG and MY.

\section{Conflict of Interest Disclosures}

None.

\section{Ethical Statement}

The ethic committee of National Institute for Medical Research Development approved the protocol of present study (Code: IR.NIMAD.REC.1397.166). In addition, subjects gave their approval in the form of informed consent during the data collection periods.

\section{Funding}

National Institute for Medical Research Development, Iran (code 965424).

\section{Acknowledgements}

We thank Mr. Hashem Hosseini for his invaluable help.

\section{References}

1. Forouzanfar MH, Afshin A, Alexander LT, Aasvang GM, Bjertness E, Htet AS, et al. Global, regional, and national comparative risk assessment of 79 behavioural, environmental and occupational, and metabolic risks or clusters of risks, 1990-2015: a systematic analysis for the Global Burden of Disease Study 2015. Lancet. 2016;388(10053):1659-1724. doi: 10.1016/S0140-6736(16)31679-8.

2. Rezaei S, Sari AA, Arab M, Majdzadeh R, Poorasl AM. Economic burden of smoking: a systematic review of direct and indirect costs. Med J Islam Repub Iran. 2016;30:397.

3. Meysamie A, Ghalehtaki R, Ghodsi S, Esteghamati A, Mohammad K, Etemad K, et al. Trend of cigarette smoking in Iranian adult population from 2000 to 2011 based on four national surveys. Soc Determ Health. 2017;3(3):148-159. doi: 10.22037/sdh.v3i3.18273.

4. Chaloupka FJ, Yurekli A, Fong GT. Tobacco taxes as a tobacco control strategy. Tob Control. 2012;21(2):172-180. doi: 10.1136/tobaccocontrol-2011-050417.

5. Henriksen L. Comprehensive tobacco marketing restrictions: promotion, packaging, price and place. Tob Control. 2012;21(2):147-153. doi: 10.1136/ tobaccocontrol-2011-050416.

6. Hammond D, Fong GT, McNeill A, Borland R, Cummings KM. Effectiveness of cigarette warning labels in informing smokers about the risks of smoking: findings from the International Tobacco Control (ITC) Four Country Survey. Tob Control. 2006;15(suppl 3):iii19-iii25. doi: 10.1136/tc.2005.012294.

7. Fong GT, Hammond D, Hitchman SC. The impact of pictures on the effectiveness of tobacco warnings. Bull World Health Organ. 2009;87(8):640-643. doi: 10.2471/BLT.09.069575.

8. International Agency for Research on Cancer, World Health Organization. Evaluating the effectiveness of smoke-free policies. Lyon, France: IARC Press, International Agency for Research on Cancer; 2009.

9. Hyland A, Barnoya J, Corral JE. Smoke-free air policies: past, present and future. Tob Control. 2012;21(2):154-161. doi: 10.1136/tobaccocontrol-2011-050389.

10. West R, Raw M, McNeill A, Stead L, Aveyard P, Bitton J, et al. Health-care interventions to promote and assist tobacco 
cessation: a review of efficacy, effectiveness and affordability for use in national guideline development. Addiction. 2015;110(9):1388-1403. doi: 10.1111/add.12998.

11. World Health Organization. WHO global report on trends in prevalence of tobacco smoking 2015. Genova: World Health Organization; 2015.

12. World Health Organization. WHO report on the global tobacco epidemic, 2017. Monitoring tobacco use and prevention policies. 2017. Geneva: World Health Organization; 2017.

13. Szklo M. Epidemiology: Beyond the Basics. Am J Epidemiol. 2001;153(8):821-822. doi: 10.1093/aje/153.8.821.

14. Hosseini M, Yousefifard M, Taslimi S, Sohanaki H, Nourijelyani $\mathrm{K}$, Asgari $\mathrm{F}$, et al. Trend of blood cholesterol level in iran: results of four national surveys during 1991-2008. Acta Med Iran. 2013;51(9):642-651.

15. World Health Organization. Global health risks: mortality and burden of disease attributable to selected major risks. Genova: World Health Organization; 2009.

16. Hajipour MJ, Djalalinia S, Sheidaei A, Yoosefi M, Zokaiee H, Damirchilu B, et al. Protocol Design for Large-Scale CrossSectional Studies of Surveillance of Risk Factors of NonCommunicable Diseases in Iran: STEPs 2016. Arch Iran Med. 2017;20(9):608-616.

17. Jamal A, Phillips E, Gentzke AS, Homa DM, Babb SD, King $\mathrm{BA}$, et al. Current cigarette smoking among adults-United States, 2016. MMWR Morb Mortal Wkly Rep. 2018;67(2):5359. doi: 10.15585/mmwr.mm6702a1.

18. Yang Y. Trends in US adult chronic disease mortality, 19601999: Age, period, and cohort variations. Demography. 2008;45(2):387-416. doi: 10.1353/dem.0.0000.

19. Yang Y, Fu WJ, Land KC. A Methodological Comparison of Age-Period-Cohort Models: The Intrinsic Estimator and Conventional Generalized Linear Models. Sociol Methodol. 2004;34(1):75-110. doi: 10.1111/j.0081-1750.2004.00148.x.

20. Asgari F, Majidi A, Koohpayehzadeh J, Etemad K, Rafei A. Oral hygiene status in a general population of Iran, 2011: a key lifestyle marker in relation to common risk factors of non-communicable diseases. Int J Health Policy Manag. 2015;4(6):343-352. doi: 10.15171/ijhpm.2015.18.

21. Reitsma MB, Fullman N, Ng M, Salama JS, Abajobir A, Abate $\mathrm{KH}$, et al. Smoking prevalence and attributable disease burden in 195 countries and territories, 1990-2015: a systematic analysis from the Global Burden of Disease Study 2015. Lancet. 2017;389(10082):1885-1906. doi: 10.1016/S01406736(17)30819-X.

22. Jha P. Avoidable global cancer deaths and total deaths from smoking. Nat Rev Cancer. 2009;9(9):655-664. doi: 10.1038/ nrc2703.

23. Jha P, FJ C. Tobacco control policies in developing countries. New York: Oxford University Press; 1999.

24. Chaloupka FJ, Warner KE, Culyer AJ, Newhouse JP. Handbook of health economics. 1 ed. Netherland: Elsevier; 2000.

25. Smith K, Gilmore A, Chaloupka F, Delipalla S. IARC handbooks of cancer prevention: tobacco control volume 14 effectiveness of price and tax policies for control of tobacco. Lyon, France: International Agency for Research on Cancer; 2011.

26. Guindon GE, Paraje GR, Chaloupka FJ. The Impact of Prices and Taxes on the Use of Tobacco Products in Latin America and the Caribbean. Am J Public Health. 2018;108(Suppl 6):S492-S502. doi: 10.2105/AJPH.2014.302396r.

27. Sharifi H, Ramezankhani A, Tafti SF, Kashani BS, Padyab M, Heydari GR. Public Awareness about Framework Convention on Tobacco Control (FCTC) in Tehran. Tanaffos. 2009;8(4):2632.

28. Sarraf-Zadegan N, Boshtam M, Shahrokhi S, Naderi GA, Asgary S, Shahparian M, et al. Tobacco use among Iranian men, women and adolescents. Eur J Public Health. 2004;14(1):7678. doi: 10.1093/eurpub/14.1.76.

29. Barikani A, Ebrahim SM, Navid M. The cause of divorce among men and women referred to marriage and legal office in Qazvin, Iran. Glob J Health Sci. 2012;4(5):184-191. doi: 10.5539/gjhs.v4n5p184.

30. Baheiraei A, Mirghafourvand M, Charandabi S-A, NEDjAt S, Mohammadi E. A population-based survey on prevalence of cigarette smoking and its socio-demographic risk factors among women of reproductive age in Tehran-Iran. Epidemiol Biostat Public Health. 2014;11(3):e9408-9401-e9408-9408.

31. Kim SK, Park JH, Lee JJ, Lee SB, Kim TH, Han JW, et al. Smoking in elderly Koreans: Prevalence and factors associated with smoking cessation. Arch Gerontol Geriatr. 2013;56(1):214219. doi: 10.1016/j.archger.2012.08.018. 